\title{
Prescription Drugs, Alcohol, and Illicit Substance Use and Their Correlations Among Medical Sciences Students in Iran
}

\author{
Abbas Abbasi-Ghahramanloo ${ }^{1}$; Akbar Fotouhi ${ }^{1}$; Hojjat Zeraati ${ }^{1}$; Afarin Rahimi-Movaghar ${ }^{2,}$ \\ ${ }^{1}$ Department of Epidemiology and Biostatistics, School of Public Health, Tehran University of Medical Sciences, Tehran, IR Iran \\ ${ }^{2}$ Iranian National Center for Addiction Studies, Iranian Institute for Reduction of High-Risk Behaviors, Tehran University of Medical Sciences, Tehran, IR Iran \\ *Corresponding author:Afarin Rahimi-Movaghar, Iranian National Center for Addiction Studies, Iranian Institute for Reduction of High-Risk Behaviors, Tehran University of Medical \\ Sciences, South Karegar Ave., P. O. Box: 1336616357, Tehran, IR Iran. Tel/Fax:+98-2155412232, E-mail: rahimia@sina.tums.ac.ir
}

Received: July 11, 2014; Revised: September 30, 2014; Accepted: October 2, 2014

\begin{abstract}
Background: Substance use among young people is a major public health problem in Iran.
Objectives: The aims of the present study were to determine the prevalence of substance misuse and its determinants in medical sciences students in Tehran, Iran.

Patients and Methods: A cross-sectional study was performed on a randomly selected sample of 1992 medical sciences students during 2012-2013. Anonymous, structured questionnaires were distributed among the students in each selected class. Substance misuse was defined according to cultural and epidemiological features. Data analysis was performed using chi-squared test, Fisher's exact test, and binary logistic regression.

Results: The prevalence of prescription drug misuse, last year alcohol use, and ever illicit substance use was 4.9\%, 6.9\%, and 2.9\%, respectively. The result of multiple logistic regression model showed that being a male $(\mathrm{OR}=4.0)$, hookah use in the last year $(\mathrm{OR}=3.2)$, prescription drug misuse $(\mathrm{OR}=3.2)$, and alcohol use in the last year $(\mathrm{OR}=3.3)$ were associated with the students' illicit substance use. Last year alcohol use $(\mathrm{OR}=5.3)$, ever illicit substance use $(\mathrm{OR}=3.2)$, and illicit substance use in friends $(\mathrm{OR}=2.6)$ were associated with prescription drug misuse.

Conclusions: Our results suggested that the prevalence of prescription drugs, alcohol and illicit substance use was relatively low, though still significant, among Iranian students, which was strongly associated with family and friends' use. The findings of this research can be used for planning and evaluating interventions by considering the risk factors and protective factors in Universities.
\end{abstract}

Keywords: Prescription Drug Misuse; Street Drugs; Students

\section{Background}

Substance use among young people is an important clinical and public health problem, mainly because of its high prevalence and the associated negative consequences. Substance use is accompanied by increased risk of morbidity and mortality, psychological and interpersonal problems, academic failure, difficulties in establishing and sustaining relationships, and experiencing unwanted or unprotected sex, crime, accidents, and injuries (1).

The consumption of legal and illegal drugs has increased around the world, including Asian countries. This increase is not just limited to mood-altering or psychoactive drugs, but it also includes many illicit drugs (2). On the other hand, adolescence and youth are in risky life cycles, during which the substance use often initiates. University or college duration is also a sensitive and critical period, because substance use could be seen, especially among students under academic pressure, peer group effects, popularity, and easy access to common substances like alcohol (3). Arria and Caldeira (4) showed that the exposure opportunity and onset of substance use often occurs in universities.
School surveys are efficient and frequently used when studying alcohol, tobacco, and substance use among young populations. Cost-effectiveness and feasibility are considered as the beneficial characteristics of school surveys. Besides, anonymity of questionnaire leads to increased confidence of students and accuracy of results (5). Accordingly, school surveys are the most common epidemiological studies on substance use in the world; examples of this type of study are the Americans Monitoring The Future (MTF) study, conducted every year since 1975 (6) and European School Survey Project on Alcohol and Other Drugs (ESPAD), performed every four years in most European countries since 1995 (7). Several studies have also been conducted in Iran among university students, which was evident by the fact that 17 studies were included in a systematic review in this domain (8). Sixteen out of 17 studies were conducted in medical universities, indicating the fact that medical sciences universities pay more attention to this matter. This systematic review showed that lifetime and last month alcohol, opium, and cannabis use were more common among Iranian stu-

Copyright (C) 2015, Zahedan University of Medical Sciences. This is an open-access article distributed under the terms of the Creative Commons Attribution-NonCommercial 4.0 International License (http://creativecommons.org/licenses/by-nc/4.0/) which permits copy and redistribute the material just in noncommercial usages, provided the original work is properly cited. 
dents. In case of daily consumption in males, opium use was the highest, followed by alcohol and cannabis use. After this review, several other studies have been conducted on students in Iran (9-11). It should be noted that because of the pressure due to heavy workload, the prevalence of substance use in medical university students may be different from the general population or other students. This pressure could lead to adverse health effects and more arbitrary use of drugs for coping with stress $(12,13)$. Additionally, medical sciences students may be at a higher risk for substance use due to their familiarity with and easier access to drugs. On the other hand, their attitudes towards substance use may affect their professional behavior. Besides, substance use by this group can create unfavorable patterns and lead to increased risk of unhealthy behaviors in the society (10). Therefore, the information obtained from substance use in medical university students can be used for formulating interventions as well as for educational and prevention programs in high-risk groups (14). In Iran, since 1986, medical universities have been part of the Ministry of Health and Medical Education and separated from nonmedical fields.

\section{Objectives}

Tehran University of Medical Sciences, with the largest number of students (approximately 16000) at different fields and levels, is the oldest and largest University of Medical Sciences in Iran. Therefore, this study was conducted to determine the status of substance use and its correlates in the students of Tehran University of Medical Sciences during 2012-2013.

\section{Patients and Methods}

The present cross-sectional study was conducted from fall 2012 to winter 2013. We used multi-stage sampling based on the proportion of students in different colleges (stratified sampling) and number of classes (clusters). Students were chosen based on the following strategy; in each college (strata), some classes (clusters) were randomly selected and all the students of the selected classes were included in the study. To gain the students' trust before distributing the questionnaires, an explanation was presented by interviewers about the purposes of the study, anonymity of the questionnaires, and the voluntary nature of participation in the survey. Furthermore, they were asked not to enter their personal information in the questionnaire. Finally, same-color pens were distributed among the students for maintaining their confidentiality.

The students who were randomly selected completed a self-report questionnaire, developed earlier in another study (15) in the classroom. The questionnaire had been prepared based on the World Health Organization (WHO) Core Questionnaires and WHO Alcohol, Smoking and Substance Involvement Screening Test (ASSIST), taking into account the situation of substance use in Iran. The content of the questionnaire had been previously validated by a group of researchers in another study (15) and the validity was assessed by pretesting the questionnaire in a class of master of public health (MPH) students.

This questionnaire begins with questions of demographic information including age, gender, marital status, and the type of residence. Other questions included smoking, hookah use, alcohol use, prescription drugs misuse (including opioid drugs, methylphenidate and sedatives or tranquilizers), illicit substance use (including cannabis, ecstasy, stimulants such as amphetamine and methamphetamine, opium and its burnt, heroin and cocaine), alcohol use, prescription drugs misuse and illicit drug use in the family members and close friends, the importance of substance use in close friends. In this paper, the term "prescription drugs misuse" refers to the use of opioid drugs and sedatives (tranquilizers) at least three times a week for the last month or the last year use of methylphenidate. Illicit substances included cannabis and similar compounds, opium (or burned, and the sap), heroin and cocaine, ecstasy, amphetamines, and other stimulants such as methamphetamine. For smoking, hookah and alcohol, the last year use was considered, while for illicit substances, lifetime use was considered for statistical analyses. The norm rate of usage of each substance was used as the selection criteria for each period. For example, in Iran, the occasional use of opioid drugs without a doctor's prescription for physical pain is widespread, but its continuous use is considered abnormal and can lead to numerous side effects.

Prevalence with 95\% confidence interval (CI) was reported. To perform simple statistical analysis, chi-squared and Fisher's exact tests were used. For assessing multiple associations of all the variables with prescription drugs, alcohol and illicit substance use, multiple binary logistic regression analysis was used separately for the outcomes. To improve the veracity and reliability of anonymous respondents, limited demographic data were recorded. The most important criterion for ensuring the representativeness of the sample was gender. Because the number of female students at Universities of Medical Sciences in Iran is about twice as males, simple ratios were used rather than weighted ones. The study was approved by the Ethics Committee of Tehran University of Medical Sciences.

\section{Results}

From 2212 distributed questionnaires, a total of 1992 (90.5\% response rate) were completed by the students. The mean age of the subjects was $21.16 \pm 3.15$ years (range: $16-44)$. The majority of sample were female (69.2\%) and $7.9 \%$ of the samples were married. Among 1992 students, 98 (4.9\%, 95\% CI: 3.4-5.9) had used prescription drugs at least three times a week for the last month. Among these, 40 (40.8\%), 9 (9.2\%) and 54 (55.1\%) of them had used opioid drugs, sedatives (tranquilizers), and methylphenidate, respectively (Table 1 ). 
Abbasi-Ghahramanloo A et al.

Table 1. Demographic Characteristics and High-Risk Variables by Prescription Drug Misuse, Alcohol Use and Illicit Substance Use in a Sample of Iranian Students

\begin{tabular}{|c|c|c|c|c|c|c|c|}
\hline \multirow[t]{2}{*}{ Characteristics } & \multicolumn{2}{|c|}{ Prescription Drugs Use $^{a}$} & \multicolumn{2}{|c|}{ Alcohol Use $^{\mathrm{b}}$} & \multicolumn{2}{|c|}{ Illicit Substance Use $^{\mathrm{C}}$} & \multirow[t]{2}{*}{ No. } \\
\hline & No. $(\%)$ & Pvalue & No. (\%) & Pvalue & No. $(\%)$ & Pvalue & \\
\hline Total & $98(4.91)$ & & $138(6.92)$ & & $57(2.86)$ & & 1992 \\
\hline Age, $y$ & & 0.794 & & 0.154 & & $0.796^{\mathrm{d}}$ & \\
\hline$\leq 25$ & $90(4.90)$ & & $131(7.14)$ & & $54(2.94)$ & & 1834 \\
\hline$>25$ & $8(5.40)$ & & $6(4.05)$ & & $3(2.02)$ & & 148 \\
\hline Gender & & 0.001 & & $<0.001$ & & $<0.001$ & \\
\hline Male & $45(7.34)$ & & $82(13.37)$ & & $42(6.85)$ & & 613 \\
\hline Female & $53(3.84)$ & & $56(4.06)$ & & $15(1.08)$ & & 1379 \\
\hline Marital status & & 0.375 & & 0.208 & & $0.466^{\mathrm{d}}$ & \\
\hline Single & $87(4.76)$ & & $130(7.11)$ & & $50(2.73)$ & & 1827 \\
\hline Married & $10(6.36)$ & & $7(4.45)$ & & $6(3.82)$ & & 157 \\
\hline Residency & & 0.063 & & $<0.001$ & & $<0.001$ & \\
\hline Parental home & $37(5.37)$ & & $42(6.09)$ & & $12(1.74)$ & & 689 \\
\hline Dormitory & $51(4.24)$ & & $78(6.49)$ & & $37(3.08)$ & & 1201 \\
\hline Single home & $7(10.14)$ & & $16(23.18)$ & & $7(10.14)$ & & 69 \\
\hline Smoking (last year) & & $<0.001$ & & $<0.001$ & & $<0.001$ & \\
\hline No & $73(4.01)$ & & $84(4.62)$ & & $33(1.81)$ & & 1816 \\
\hline Yes & $25(14.20)$ & & $54(30.68)$ & & $24(13.63)$ & & 176 \\
\hline Hookah use (last year) & & $<0.001$ & & $<0.001$ & & $<0.001$ & \\
\hline No & $61(3.72)$ & & $37(2.25)$ & & $25(1.52)$ & & 1638 \\
\hline Yes & $37(10.45)$ & & $101(28.53)$ & & $32(9.03)$ & & 354 \\
\hline Alcohol use (last year) & & $<0.001$ & & & & $<0.001^{\mathrm{d}}$ & \\
\hline No & $72(3.88)$ & & - & - & $34(1.83)$ & & 1854 \\
\hline Yes & $26(18.84)$ & & - & & $23(16.66)$ & & 138 \\
\hline Prescription drug misuse & & & & $<0.001$ & & $<0.001^{\mathrm{d}}$ & \\
\hline No & - & - & $112(5.92)$ & & $44(2.32)$ & & 1889 \\
\hline Yes & - & & $26(26.53)$ & & $13(13.26)$ & & 98 \\
\hline Illicit substance use & & $<0.001^{\mathrm{d}}$ & & $<0.001^{\mathrm{d}}$ & & & \\
\hline No & $85(4.39)$ & & $115(5.94)$ & & - & - & 1935 \\
\hline Yes & $13(22.80)$ & & $23(40.35)$ & & - & & 57 \\
\hline Illicit substance use in family (last year) & & 0.811 & & 0.048 & & $0.042^{\mathrm{d}}$ & \\
\hline No & $88(4.87)$ & & $120(6.44)$ & & $48(2.65)$ & & 1806 \\
\hline Yes & $7(4.45)$ & & $17(10.82)$ & & $9(5.73)$ & & 157 \\
\hline Illicit substance use in friends (last year) & & $<0.001$ & & $<0.001$ & & $0.004^{\mathrm{d}}$ & \\
\hline No & $79(4.33)$ & & $102(5.59)$ & & $46(2.52)$ & & 1824 \\
\hline Yes & $16(11.67)$ & & $35(25.54)$ & & $10(7.29)$ & & 137 \\
\hline Alcohol use in family (last year) & & 0.139 & & $<0.001$ & & 0.002 & \\
\hline No & $77(4.55)$ & & $77(4.55)$ & & $41(2.42)$ & & 1692 \\
\hline Yes & $18(6.61)$ & & $61(22.42)$ & & $16(5.88)$ & & 272 \\
\hline Alcohol use in friends (last year) & & 0.011 & & $<0.001$ & & 0.016 & \\
\hline No & $62(4.14)$ & & $43(2.87)$ & & $35(2.34)$ & & 1494 \\
\hline Yes & $33(7.00)$ & & $94(19.95)$ & & $21(4.45)$ & & 471 \\
\hline Prescription drug misuse in family (last year) & & 0.068 & & 0.471 & & 0.238 & \\
\hline No & $57(4.23)$ & & $97(7.21)$ & & $35(2.60)$ & & 1345 \\
\hline Yes & $38(6.15)$ & & $39(6.32)$ & - & $22(3.56)$ & & 617 \\
\hline $\begin{array}{l}\text { Prescription-type drug misuse in friends (last } \\
\text { year) }\end{array}$ & & 0.006 & & $<0.001$ & & 0.727 & \\
\hline No & $55(4.00)$ & & $70(5.10)$ & & $38(2.76)$ & & 1372 \\
\hline Yes & $41(6.85)$ & & $67(11.37)$ & & $18(3.05)$ & & 589 \\
\hline
\end{tabular}

${ }^{\mathrm{a}}$ Use of opioid drugs and sedatives (tranquilizers) at least three times a week for the last month or last year use of methylphenidate.

$\mathrm{b}$ Use of alcohol in the last year.

${ }^{\mathrm{c}}$ Lifetime use of any illicit substance (e.g. cannabis, ecstasy, amphetamine and methamphetamine, opium, heroin, and cocaine).

$\mathrm{d}$ Fisher's exact test. 
Abbasi-Ghahramanloo A et al.

Table 2. Logistic Regression Analysis of the Association Between Prescription Drugs Misuse, Alcohol Use and Illicit Substance Use and High-Risk Variables in a Sample of Iranian Students ${ }^{\mathrm{a}}$

\begin{tabular}{|c|c|c|c|c|c|c|c|c|c|}
\hline \multirow[t]{2}{*}{ Variables } & \multicolumn{3}{|c|}{ Prescription Drug Use ${ }^{b}$} & \multicolumn{3}{|c|}{ Alcohol Use ${ }^{c}$} & \multicolumn{3}{|c|}{ Illicit Substance Use $^{\mathrm{d}}$} \\
\hline & OR & 95\% CI & P value & OR & 95\% CI & Pvalue & OR & 95\% CI & Pvalue \\
\hline Being a male & - & - & - & - & - & - & 4.02 & $1.88-8.60$ & $<0.001$ \\
\hline Smoking (last year) & - & - & - & 5.47 & $2.83-10.58$ & $<0.001$ & - & - & - \\
\hline Hookah use (last year) & - & - & - & 8.30 & $4.58-15.03$ & $<0.001$ & 3.23 & $1.51-6.90$ & 0.002 \\
\hline Prescription drug misuse & - & - & - & 5.51 & $2.41-12.54$ & $<0.001$ & 3.23 & $1.33-7.82$ & 0.009 \\
\hline Alcohol use (last year) & 5.29 & $2.65-10.56$ & $<0.001$ & - & - & - & 3.35 & $1.52-7.38$ & 0.003 \\
\hline Illicit substance use & 3.22 & $1.30-7.95$ & 0.011 & 3.52 & $1.45-8.54$ & 0.005 & - & - & - \\
\hline $\begin{array}{l}\text { Alcohol use in family (last } \\
\text { year) }\end{array}$ & - & - & - & 3.38 & $1.80-6.34$ & $<0.001$ & - & - & - \\
\hline $\begin{array}{l}\text { Alcohol use in friends (last } \\
\text { year) }\end{array}$ & - & - & - & 3.88 & $2.06-7.33$ & $<0.001$ & - & - & - \\
\hline $\begin{array}{l}\text { Illicit substance use in } \\
\text { friends (last year) }\end{array}$ & 2.58 & $1.20-5.55$ & 0.015 & - & - & - & - & - & - \\
\hline $\begin{array}{l}{ }^{a} \text { Abbreviations: CI, confidence in } \\
b_{\text {Variables entered in step 1: ge }} \\
\text { family, illicit substance use in fri } \\
{ }^{c} \text { Variables entered in step 1: gen } \\
\text { family, alcohol use in friends, illi } \\
{ }^{d} \text { Variables entered on step 1: ger } \\
\text { use in friends, prescription drug }\end{array}$ & $\begin{array}{l}\text { l; OR, } \\
\text { age, } n \\
\text { prescr } \\
\text { ge, m } \\
\text { stanc }\end{array}$ & $\begin{array}{l}\text { s ratio. } \\
\text { tal status, re } \\
\text { on drug use } \\
\text { al status, res } \\
\text { se in family, }\end{array}$ & $\begin{array}{l}\text { idency, sm } \\
\text { family, an } \\
\text { lency, smo } \\
\text { id illicit su }\end{array}$ & $\begin{array}{l}\text { g, hoo } \\
\text { escrip } \\
\text {, hook } \\
\text { nce us }\end{array}$ & $\begin{array}{l}\text { use, alcoh } \\
\text {-type drug } \\
\text { Ise, prescri } \\
\text { friends. }\end{array}$ & $\begin{array}{l}\text { Ise, illicit } \\
\text { in friends } \\
\text { on drug u }\end{array}$ & licit & illicit subs & $\begin{array}{l}\text { ho use in } \\
\text { hol use in } \\
\text { substance }\end{array}$ \\
\hline
\end{tabular}

Of the respondents, 138 (6.9\%, 95\% CI: 5.8-8.0) had used alcohol in the last year and 57 (2.9\%, 95\% CI: 2.1-3.6) had never used illicit substances. Among the never users of illicit substances, some of them reported the use of cannabis $(23,40.3 \%)$, ecstasy $(6,10.5 \%)$, methamphetamine $(5,8.8 \%)$, opium $(26,45.6 \%)$, heroin $(2,3.5 \%)$, and cocaine $(8,14 \%)$. Table 1 presents the demographic characteristics of substance users and the association between prescription drug misuse, alcohol use, and illicit substance use (Table1).

Table 2 indicates the results of binary logistic regression. The results of these analyses showed that alcohol use in the last year $(O R=5.3)$, illicit substance use $(O R=$ 3.2 ), and illicit substance use among friends $(\mathrm{OR}=2.6)$ were associated with prescription drug misuse. This table also shows the association of smoking in the last year (OR $=5.5)$, hookah use in the last year $(\mathrm{OR}=8.3)$, prescription drugs misuse $(\mathrm{OR}=5.5)$, illicit substance use $(\mathrm{OR}=3.5)$, alcohol use in the family members $(\mathrm{OR}=3.4)$, and alcohol use among friends in the last year $(\mathrm{OR}=3.9)$ with alcohol use among university students.

Results of the logistic model also showed that being a male $(\mathrm{OR}=4.0)$, hookah use in the last year $(\mathrm{OR}=3.2)$, prescription drug misuse $(\mathrm{OR}=3.2)$, and alcohol use in the last year $(\mathrm{OR}=3.3)$ were associated with students' illicit substance use.

\section{Discussion}

In the present study, the prevalence of prescription drug misuse was $4.9 \%$. Separated results based on the drugs are as follows: about $2.7 \%$ of the students had used methylphenidate in the last year. Methylphenidate is used in medical sciences students for increasing the learning abilities and academic achievement. It can be easily used and considered to be stigma-free (16). In an earlier, smaller study in another Iranian university, methylphenidate use in the last year was $6.4 \%(17)$. The prevalence of methylphenidate use in our study was comparable to studies from the Medical University Students. In the MTF study in the US, $1.8 \%$ of the students had used Ritalin in the last year (6). It seems that some Medical University Students did not have a negative attitude toward nonmedical use of methylphenidate. This can be warning for the dissemination of methylphenidate use in young people in Iranian Universities.

The prevalence of sedatives (tranquilizers) use (at least three times a week for the last month) was $0.4 \%$, which was lower than the prevalence reported in studies from other countries. For example, in the MTF study, nonprescription uses of sedatives and tranquilizers in the last 30 days were $0.8 \%$ and $1.1 \%$ among students, respectively (6). In European countries, in a recent ESPAD study (7), on average, $6 \%$ of the students reported lifetime nonmedical use of tranquilizers or sedatives, ranging from $15 \%$ and $14 \%$ in Poland and France respectively to $2 \%$ in Ukraine, Russia, and Germany.

About 2.0\% of all the students had misused (at least three times a week for the last month) prescription opioid drugs. In most Iranian studies regarding nonmedical use of drugs in students, the prevalence of each drug 
had been reported separately. For example, the result of a study from Guilan University of Medical Sciences showed that $0.36 \%$ of students used Morphine during the last 30 days (18). Another study showed that the prevalence of tramadol use in university students was $9.5 \%$ in the last 30 days (19). These differences probably are due to different definitions of prescription opioid drugs use and the study location. The resulted prevalence in our study was similar to those on students in the Medical University Students. In the MTF study (6), $2.2 \%$ of the students had used narcotics other than heroin (e.g. methadone, morphine, codeine, etc.).

The prevalence of alcohol use in the last year was 6.9\% (13.4\% in male and $4.1 \%$ in female students), which was lower than that of other studies. In the MTF study in the US, 79.2\% of students had reported alcohol use in the last year (6). This rate is even lower than that reported in some Islamic countries. For example, in a study in Turkey, $48.5 \%$ of students had used alcohol in the last year (20). Lower rate of alcohol use in this study is mostly related to the following reasons: 1 ) religious and legal prohibition of alcohol use; 2) the cultural stigma against alcohol use; and 3 ) disapproval of alcohol use by parents. The prevalence of alcohol use in this study is similar to other studies in Iran (21, 22). Based on a review study, the lifetime prevalence of alcohol consumption in Iranian students varied between $5 \%$ and $34.7 \%$ (8).

Our findings indicated that the lifetime prevalence of illicit substance use was 2.9\%. Taremian and Bolhari (21) reported that the lifetime prevalence of opium (the most common illicit drug used in Iran) and heroin in universities of Tehran was $2.3 \%$ and $2.2 \%$, respectively. Results of studies conducted in other countries are very different from our results. For example, in the MTF study, 50.5\% of the students had a history of any illicit substance use; however, after putting marijuana aside, this rate reached $23.8 \%$ (6). The results from the European study (ESPAD) (7) also indicated that on average, $6 \%$ of European students had lifetime use of illicit drugs other than cannabis, with France having the highest rate (11\%). In Pakistan, $17 \%$ of the students reported history of any psychoactive substances use (23). In the MTF study, the lifetime prevalence of use of marijuana, inhalants, hallucinogens, cocaine, and heroin were $49.1 \%, 5.7 \%, 7.6 \%, 5.2 \%$, and $0.5 \%$, respectively (6). Our analysis showed that opium was the most frequently used drug among students (45.6\% of the users of illicit drug). In general, because of the domestic reasons and high availability due to the close proximity to Afghanistan, opium consumption is more common in Iran (24). Therefore, in addition to differences in the prevalence rate, the pattern of substance use in Iranian students is completely different from students of western countries.

Our findings suggested that the prevalence of prescription drug misuse, alcohol use, and illicit substance use in male students was much higher than in female students (7.3\% vs. $3.8 \%, 13.4 \%$ vs. $4.1 \%$, and $6.8 \%$ vs. $1.1 \%$, respectively). Studies conducted in Iran and other countries have shown that the prevalence of prescription drug misuse, alcohol use, and illicit substance use was more in males than in females $(18,25-28)$. However, after entering all the variables into the logistic model, the effects of gender on the use of prescription drug and alcohol were adjusted. The remaining difference could be due to other factors such as consumers in family and friends. However, the results of this analysis showed that regardless of other factors, being a male increases the chance of lifetime illicit substance use by about four times.

Co-occurrence is one of the most effective approaches in the prevention of high-risk behaviors. Numerous studies have emphasized on the co-occurrence of substance use and other risky behaviors $(29,30)$. Our findings indicated that prescription drug misuse, alcohol use, and illicit substance use were strongly associated with each other, as well as with other high-risk behaviors (eg, cigarette and hookah smoking in the last year).

One of the most important factors that influences the spread of substance use is peers and friends' effect. Youths who have drug-using friends are more likely to have the tendency towards substance use (31). Therefore, if close friends are substance users and substance use is common in a large group of peers, these youths are more likely to be pushed to consumption $(32,33)$. Several studies have also shown that substance user parents increases the risk of substance use in children $(34,35)$. Our study showed that there was a significant association between the use of substances in students with the use of substances in their family members and friends. For example, alcohol use in family members and close friends increases the odds of alcohol use in students by three to four times.

The strengths of the present work were its large sample size and high response rate, both of which increase the generalizability of the findings. The present work also had the following limitations: first, due to the cross-sectional design of the study, causality could not be assessed. Second, the study relied on self-report data; thus, underreporting of substance use was expected, even assuring the participants of the anonymity of the questionnaires. This study reported the prevalence of some types of substance use and determined some of theirs associated factors. The results also indicated that the prevalence of prescription drugs misuse, alcohol use, and illicit substance use was relatively low among Iranian university students, though still important. Longitudinal studies are required to determine and monitor the incidence rate of substance use and its correlates. The findings of this study can be used for planning and evaluating interventions by considering the risk factors as well as protective factors of substance use in universities.

\section{Authors' Contributions}

All the authors were involved in study conceptualization, design, quality control and interpretation of the results. Abbas Abbasi-Ghahramanloo directed the field 
work and drafted the manuscript. All the authors contributed to the final version of the manuscript.

\section{Funding/Support}

The present work was part of a master's thesis of epidemiology and was financially supported by Tehran University of Medical Sciences.

\section{References}

1. Galea S, Nandi A, Vlahov D. The social epidemiology of substance use. Epidemiol Rev. 2004;26:36-52.

2. United Nations Office for Drugs and Crime.. World Drug Report 2010.: United Nations Publications; 2010.

3. Patel DR, Greydanus DE. Substance abuse: a pediatric concern. Indian J Pediatr. 1999;66(4):557-67.

4. Arria AM, Caldeira KM, O'Grady KE, Vincent KB, Fitzelle DB, Johnson EP, et al. Drug exposure opportunities and use patterns among college students: results of a longitudinal prospective cohort study. Subst Abus. 2008;29(4):19-38.

5. United Nations for Drugs and Crime.. Conducting school surveys on drug abuse.: United Nations Publications; 2003.

6. Johnston LD, O'Malley PM, Bachman JG, Schulenberg JE. Monitoring the Future (MTF), National survey results on drug use, 1975-2012: Volume 2, College students and adults ages 19-50.Ann Arbor: University of Michigan Institute for Social Research; 2012.

7. Hibell B, Guttormsson U, Ahlstrom S, Balakireva O, Bjarnason T, Kokkevi A, et al. The 2011 ESPAD report: Substance use among students in 36 European countries.Stockholm: The Swedish Council for Information on Alcohol and Other Drugs (CAN); EMCDDA; Council of Europe; 2012.

8. Rahimi Movaghar A, Sahimi Izadian E, Younesian M. The drug use situation in university students in Iran: A literature review. Payesh Health Monit J. 2006;5(2):83-104.

9. Sahraian A, Sharifian M, Omidvar B, Javadpour A. Prevalence of substance abuse among the medical students in Southern Iran. Shiraz E Med J. 2010;11(4):198-202.

10. Ahmadi J, javadpour A, Pridmore S. Epidemiology of Substance Use among Dentistry Students (Shiraz-Iran). Iran J Psychiatry Behav Sci. 2009;3(2):25-8.

11. Mohammadpoorasl A, Ghahramanloo AA, Allahverdipour H. Risk-taking behaviors and subgrouping of college students: a latent class analysis. Am J Mens Health. 2013;7(6):475-81.

12. Yousafzai AW, Ahmer S, Syed E, Bhutto N, Iqbal S, Siddiqi MN, et al. Well-being of medical students and their awareness on substance misuse: a cross-sectional survey in Pakistan. Ann Gen Psychiatry. 2009;8:8.

13. Ahmadi J, Hasani M. Prevalence of substance use among Iranian high school students. Addict Behav. 2003;28(2):375-9.

14. Crofton JW, Freour PP, Tessier JF. Medical education on tobacco: implications of a worldwide survey. Tobacco and Health Committee of the International Union against Tuberculosis and Lung Disease (IUATLD). Med Educ. 1994;28(3):187-96.

15. Amin-Esmaeili M, Rahimi-Movaghar A, Yunesian M, Sahimi-Izadian E, Moinolghorabaei M. Trend of smoking among students of Tehran University of Medical Sciences: results from four consecutive surveys from 2006 to 2009 . Med J Islam Repub Iran. 2013;27(4):168-78.

16. Rahimi-Movaghar A, Khastoo G, Moinolghorabaei M, Yunesian
M, Sadeghi AR. Use of stimulant substances among university students in tehran: a qualitative study. Iran J Psychiatry Behav Sci. 2011;5(2):32-42.

17. Habibzadeh A, Alizadeh M, Malek A, Maghbooli L, Shoja MM, Ghabili K. Illicit methylphenidate use among Iranian medical students: prevalence and knowledge. Drug Des Devel Ther. 2011;5:71-6

18. Zarrabi H, Najafi K, Kafi M, Shirazi M. Substance Use among Students of Guilan University of Medical Sciences in Iran in 20052006. Acta Medica Iranica. 2009;47(6):473-8.

19. Fathi Y, Bashrian S, Barati M, Hazavei SMM. Tramadol abuse status and related factors among three college students in Hamadan. Scientific J Hamadan Univ Med Sci. 2012;19(3):23-9.

20. Ozgur Ilhan I, Yildirim F, Demirbas H, Dogan YB. Alcohol use prevalence and sociodemographic correlates of alcohol use in a university student sample in Turkey. Soc Psychiatry Psychiatr Epidemiol. 2008;43(7):575-83.

21. Taremian F, Bolhari J, Pairavi H, Ghazi Tabatabaeii M. The Prevalence of Drug Abuse among University Students in Tehran. Iran J Psychiatry Clin Psychol. 2008;13(4):335-42.

22. Mohammadpoorasl A, Ghahramanloo AA, Allahverdipour H, Augner C. Substance abuse in relation to religiosity and familial support in Iranian college students. Asian J Psychiatr. 2014;9:41-4.

23. Imran N, Haider II, Bhatti MR, Sohail A, Zafar M. Prevalence of Psychoactive Drug Use Among Medical Students in Lahore. Annals King Edward Med Univ. 2012;17(4).

24. Noohi S, Azar M, Behzadi AH, Sedaghati M, Panahi SA, Dehghan N, et al. A comparative study of characteristics and risky behaviors among the Iranian opium and opium dross addicts. J Addict Med. 2011;5(1):74-8.

25. Ahmadi J, Maharlooy N, Alishahi M. Substance abuse: prevalence in a sample of nursing students. J Clin Nurs. 2004;13(1):60-4.

26. Nolen-Hoeksema S. Gender differences in risk factors and consequences for alcohol use and problems. Clin Psychol Rev. 2004;24(8):981-1010.

27. McCabe SE, Knight JR, Teter CJ, Wechsler H. Non-medical use of prescription stimulants among US college students: prevalence and correlates from a national survey. Addiction. 2005;100(1):96106.

28. Greenfield SF, Back SE, Lawson K, Brady KT. Substance abuse in women. Psychiatr Clin North Am. 2010;33(2):339-55.

29. Tapert SF, Aarons GA, Sedlar GR, Brown SA. Adolescent substance use and sexual risk-taking behavior. $J$ Adolesc Health. 2001;28(3):181-9.

30. Santelli JS, Robin L, Brener ND, Lowry R. Timing of alcohol and other drug use and sexual risk behaviors among unmarried adolescents and young adults. Fam Plann Perspect. 2001;33(5):200-5.

31. Ary DV, Tildesley E, Hops H, Andrews J. The influence of parent sibling, and peer modeling and attitudes on adolescent use of alcohol. Int J Addict. 1993;28(9):853-80.

32. Bauman KE, Botvin GJ, Botvin EM, Baker E. Normative expectations and the behavior of significant others: an integration of traditions in research on adolescents' cigarette smoking. Psychol Rep. 1992;71(2):568-70.

33. Epstein JA, Botvin GJ, Baker E, Diaz T. Impact of social influences and problem behavior on alcohol use among inner-city Hispanic and black adolescents. J Stud Alcohol.1999;60(5):595-604.

34. Beman DS. Risk factors leading to adolescent substance abuse. Adolescence. 1995;30(117):201-8.

35. Maltzman I, Schweiger A. Individual and family characteristics of middle class adolescents hospitalized for alcohol and other drug abuse. Br J Addict. 1991;86(11):1435-47. 